is noteworthy that the most successful case had previously taken in vain croton-chloral hydrate and tinctura gelsemini, whereas one of the but partially successful cases was at once relieved by croton-chloral hydrate. Unfortunately, I know of no difference between the cases. In one case of brachialgia great relief was experienced after a vast variety of drugs had been futilely exhibited. One case of paroxysmal sneezing and two of severe pain in the feet with no apparent cause were relieved.

Hove.

\section{SUICIDE APPARENTLY BY AN ATTEMPT TO CUT OFF THE HEAD FROM BEHIND.} By James LitTtle, M.D.

I NOTICE in THE LANCET of June 22nd, the record of a case under the care of $\mathrm{Mr}$. Hulke of suicide apparently begun by an attempt to cut off the head from behind. The forensic interest attached to this case induces me to publish the details of an even more determined case which occurred in my practice on July 2nd, 1879.

The case was that of a woman, aged thirty-six, who had been discharged apparently cured about a week before from Garlands Asylum, where she had been an inmate about three months, with the symptoms of puerperal insanity. About $8 \mathrm{~A}$. M. on the above date the daughter of the patient came for me saying that her mother had attempted to commit suicide, and on arriving at the house I met a ghastly spectacle. She had a knife in her hand, and on the back of her neck was a huge wound, which had apparently taken half her head off. It had gone through skin, muscles, ligaments, the very bone itself, and had opened into the spinal canal, but had not touched the cord. The head itself, having lost all its connexions at the back, was bobbing about in a manner that would have been ludicrous had it not been so ghastly. The instrument was a blunt and rusty table knife, with which she had been peeling potatoes. On being questioned as to her object in committing suicide, her only reply was that she did not know. Such treatment as was possible was applied, but she died on the sixth day from septicæmia. No post-mortem was obtained.

The chief interest of the case lies in the fact of the wound having undoubtedly been committed by herself, and in the very determined manner in which she had set to work apparently to decapitate herself.

Maryport.

\section{ACUTE PEMPHIGUS RESULTING FROM THE INHALATION OF SEWER AIR.}

By MaRK STYLE, L.R.C.P.L., M.R.C.S.

I HAVE lately had under my care two cases of what I have ventured to call acute pemphigus, which I attributed to poisoning from sewer gases. Both cases occurred in children, aged five and two years respectively. On being called to the elder child, my first patient, I was informed that he had been ailing for the past fortnight or so, losing colour and appetite. On the previous day two blebs appeared, one on the sole of the foot and another on the shin of the same leg. During my attendance others followed at irregular times during the following fortnight, chiefly on the thighs and legs, and two or three on the abdomen. There was some irritation from them, accompanied by febrile symptoms, anorexia, and constipation. The younger child's was a milder but similar attack, having only two or three bullæ, which did not recur after the first week.

The treatment I adopted was quinine internally, an occasional alterative powder, baths of warm oatmeal and water, and zinc ointment and calamine lotion locally. I find that Hebra and other authorities deny the existence of acute pemphigus, but class all acute bullo as erythema bullosa, although since several cases have been reported. In my cases there was no erythema; each bulla was distinct, and until it attained some size had no inflammatory redness, even in the immediate vicinity; there were no smaller vesicles, as in herpes; nor was the skin of the part markedly red, as in erythema bullosa. I believe, too, that erythema bullosa occurs chiefly on the trunk and upper extremities; in both my cases the upper extremities were free. As both mother and nurse were particularly careful about the children's diet, which consisted mainly of milk and farinaceous food, I was rather at a loss to account for the presence of the eruption, until on making inquiries $I$ found that a nasty smell had been noticed several times in the passage immediately outside the nursery. On inspecting the bath. room, situated just outside the nursery door, I found that the housemaid's sink was acting as a very efficient ventilator to the main sewer, the overflow pipe from the bath was joined to the down pipe from the sink, and although it had a $U$ bend in it, which probably contained no water, as the bath was little used, there was a clean cut into the lumen of the pipe between the trap and the sink-pipe, so that we had a constant stream of sewer emanations entering the warm nursery by night and day. I concluded from my discoveries that this most insanitary condition of things was the cause of the illness; at any rate the evil was quickly remedied, and the children were soon well again. I may add this house was let with " all the latest sanitary improvements." If these cases were not cases of "acute pemphigus," may I call it pemphigus with acute symptoms? Bromyard.

\section{HIGH TEMPERATURE IN CHILDREN.} By W. J. Tyson, M.D.

IT is a well-known clinical fact how quickly the body temperature changes in children, and without this knowledge we should be constantly alarmed; yet I am afraid most of us do not really appreciate the above condition until we have been some years in practice. The cases that I am particularly referring to are those in which one is called to at night, with a temperature of $102^{\circ}$ to $104^{\circ}$, pulse varying from 100 to 150 , but the respiration, as a rule, not increased in the same ratio. On visiting the child the next morning the temperature is normal, or even subnormal, and the child apparently perfectly well. Some men will say that the medicine ordered, such as tincture of aconite, in drop doses frequently, a cooling saline, or a little grey powder, has been the means of lowering the heat. This may or may not be so, but my object in sending this note is rather to seek for a cause of the temperature than for the treatment of it. The most common cause is probably, I suppose, some form of error in diet, the offending food acting as an irritant upon the heat centre; another common cause is, I think, really a sunstroke; children in playing constantly throw off their caps and hats, and are exposed to the sun for many minutes. Doubtless there are other causes, but the above are the ones most commonly met with. The prevalent practice of people keeping their own clinical thermometers leads, in my experience, to the seeking of professional advice rather than the avoidance of it.

Folkestone.

\section{A SIMPLE REMEDY FOR THRUSH AND SORDES.}

By W. Theophilus Ord, M.R.C.S., L.R.C.P., IATE RESIDENT SURGEON, BIRMINGHAM GENERAL DISPENSARY.

AMrongst the ill-fed children of the poorest residents of our large cities thrush is an extremely common and troublesome complaint. The following lotion, to be applied frequently with a feather or brush to the white patches, kills the oidium albicans more quickly than any other I know, and removes the patches after a few applications, leaving healthy mucous membrane. It consists of equal parts of lotio nigra and glycerine mixed. I attribute its action to the germicidal power of the mercury. The quantity used is so small as to be quite harmless. Another condition in which I have found the same lotion invaluable is in that of the sordes which collect so abundantly on the teeth, lips, and tongue in many cases of enteric fever. It cleans these parts as if by magic, and renders that unpleasant process known as "scraping the tongue" quite unnecessary. It may also with advantage be painted over the fauces \&c. in those unhealthy conditions of the throat which are so common in typhoid. I tried it in one case of catarrhal stomatitis, but it had no effect, whereas chlorate of potash effected an immediate cure. Also in the sordes of advanced phthisis it seems to be of no use. Not having seen this lotion mentioned in any book, and having found 